\title{
Navigating the Myriad of von Willebrand Factor Assays
}

Emmanuel J. Favaloro $1,2,3$

\author{
${ }^{1}$ Department of Haematology, Institute of Clinical Pathology and \\ Medical Research (ICPMR), NSW Health Pathology, Westmead \\ Hospital, Westmead NSW, Australia \\ 2 Sydney Centres for Thrombosis and Haemostasis, Westmead \\ Hospital, Westmead NSW, Australia \\ ${ }^{3}$ School of Biomedical Sciences, Charles Sturt University, Wagga \\ Wagga, New South Wales, Australia
}

Hämostaseologie 2020;40:431-442.
Address for correspondence Emmanuel J. Favaloro, PhD, FFSc (RCPA), ICPMR, NSW Health Pathology, Westmead Hospital, Westmead NSW 2145, Australia (e-mail: emmanuel.favaloro@health.nsw.gov.au).

Abstract
Keywords
- von Willebrand factor
- von Willebrand
disease
- classification
- diagnosis

von Willebrand factor (VWF) represents a large and complex adhesive plasma protein whose main function is to provide a bridge between blood platelets and damaged endothelium, and thus facilitate primary hemostasis. VWF also binds to FVIII, preventing early proteolysis, and delivers this cargo to sites of vascular injury, thereby promoting clot formation and secondary hemostasis. An absence, deficiency, or defect in VWF can lead to a bleeding diathesis called von Willebrand disease (VWD), considered the most common inherited bleeding disorder. Contemporary laboratory assays used in VWD diagnosis/exclusion comprise a myriad of assays that identify the quantity (level) of VWF, as well as the multitude of VWF activities. These may use the following test abbreviations: VWF:Ag, VWF:RCo, VWF:CB, VWF:GPIbR, VWF:GPIbM, VWF:FVIIB, VWF:Ab. The current review explains what these assays are, as well as their place in VWD diagnostics.

\section{Introduction}

von Willebrand factor (VWF) represents a large and complex adhesive plasma protein whose main function is to provide a bridge between blood platelets and damaged endothelium. ${ }^{1}$ Thus, tissue injury, leading to endothelial cell damage, exposes subendothelial matrix proteins, such as collagen, to which VWF can bind. In addition, VWF can also bind to activated platelets via the VWF-binding receptor, glycoprotein Ib (GPIb). Thus, VWF can act as a bridge between the two, and in essence provides a kind of "mortar" to the "bricks" that platelets represent in the "brickwall" called a platelet thrombus. Consequently, VWF is a key component of primary hemostasis.

Nevertheless, VWF actually displays a multitude of "activities," and is represented by a variety of forms of increasing size or molecular weight (MW). ${ }^{2}$ One key additional activity of VWF is to bind, and stabilize the activity of, coagulation factor (F) VIII (FVIII). ${ }^{1}$ By binding to FVIII, VWF helps to prevent its proteolysis and extends the FVIII half-life in plasma. Indeed, VWF transports FVIII to sites of vascular damage, and unloads this cargo (FVIII) to such localized regions. FVIII is then deployed to promote hemostasis and thrombin generation, and eventually this supports the conversion of fibrinogen to fibrin, and further supports thrombus formation. Consequently, VWF is also a key component of secondary hemostasis.

As noted briefly above, VWF is present in plasma as protein moieties of increasing MW, as created by a process of multimerization of individual molecules of VWF. The activities (or individual functions) of VWF, including adhesion to platelets and collagen, and binding of FVIII, all happen on individual molecules of VWF. What the increasing MW achieves is the addition of multiple functional sites to a "single" protein moiety. Thus, a high MW (HMW) form of VWF carries in total a greater number of adhesive sites than does a small MW form. It is also helpful for readers to received

April 1, 2020

accepted after revision

May 18, 2020 (c) 2020 Georg Thieme Verlag KG Stuttgart · New York
DOI https://doi.org/ 10.1055/s-0040-1713735. ISSN 0720-9355. 
consider VWF as a kind of "sticky string"-the larger the sticky string, the more platelets that can be bound to the damaged endothelium, and thus the stronger the overall platelet thrombus.

\section{von Willebrand Disease}

An absence, deficiency, or defect in VWF can lead to a bleeding diathesis called von Willebrand disease (VWD). ${ }^{2-6}$ Indeed, VWD is reportedly the most common inherited bleeding disorder, potentially affecting up to $1 \%$ of the population according to epidemiological data, although the number based on presentation to clinics is closer to $0.1 \%{ }^{3}$ There are currently six defined "types" of VWD": types 1 and 3 , respectively, define partial and ("virtually") complete loss of VWF, and the residual four types of VWD are classified within type 2, representing "qualitative" defects of VWF, as expressing loss of VWF activity or functionality. Type 2 VWD may also be compounded by quantitative reduction in $\mathrm{VWF}^{4}$

In type $1 \mathrm{VWD}$, the quantity of plasma VWF is lower than that in normal individuals, but the relative activity of the VWF is the same as in normal individuals. ${ }^{4-7}$ Expanding the analogy of the "sticky string," this means less "sticky string" in plasma in total, but any "sticky string" remaining has the same adhesive functionality as normal VWF. The ISTH (International Society on Thrombosis and Hemostasis) SSC (Scientific Standardization Committee) on VWF has defined type 3 VWD as "virtually" complete loss of $\mathrm{VWF}^{4}$ since it is sometimes difficult with existing laboratory assays to identify "complete" loss due to issues with detection and quantitation of low levels of VWF. ${ }^{8}$ Thus, there may be an overlap in what one diagnostic center may call type 3 VWD, and another center may call "severe" type 1 VWD. Irrespective, type 3 VWD represents the most severe form of VWD and patients will present with greater disease symptomatology. In type $3 \mathrm{VWD}$, not only is VWF absent, but FVIII is also very low (generally $<10 \mathrm{U} / \mathrm{dL}$ ), since absence of protection by VWF leads to proteolysis of "free" FVIII and thus fast clearance from circulation. Consequently, patients with type 3 VWD suffer from both primary and secondary hemostasis-related bleeding.

Type 2 VWD is categorized into four different types according to the latest classification scheme ${ }^{4}$ : (1) type $2 \mathrm{~A} V \mathrm{VD}$, characterized by a loss of HMW forms of VWF; these patients also display a reduction in overall quantity of plasma VWF. Furthermore, their bleeding diathesis may be severe since the HMW VWF forms would typically otherwise display greatest overall adhesiveness and functionality. (2) Type 2B VWD, characterized by a hyper-adhesive form of VWF that leads to "spontaneous" binding of VWF to the platelet GPIb receptor, and then clearance of both platelets and (HMW) VWF, given the HMW VWF forms display greatest overall adhesiveness. Thus, type 2B VWD is often also characterized by a loss of HMW forms of VWF, as well as by thrombocytopenia (typically "mild"). (3) Type 2N VWD, representing a loss of FVIII binding. These patients phenotypically present with a disproportionally lower level of measurable FVIII, given their VWF is no longer able to bind and protect FVIII. Consequently, their bleeding expresses primarily as a secondary hemostasis defect, and indeed, differential diagnosis from patients with hemophilia A (representing a loss of FVIII) is typically the most pressing diagnostic challenge. Differential diagnosis is nonetheless important, given differing therapy (VWF replacement in 2N VWD; FVIII replacement in hemophilia A). (4) Type 2M VWD, representing a fairly heterogeneous group of qualitative defects affecting VWF, but not characterized by ("significant") loss of HMW VWF. 2M VWD is perhaps the most underrecognized and misunderstood form of VWD, and is more typically "misdiagnosed" as either type 1 or $2 \mathrm{~A} \mathrm{VWD} .^{9}$ The simplest way to think of 2M VWD is to essentially consider it a diagnosis of exclusion, thus, if a patient does not have types 1 , $2 \mathrm{~A}, 2 \mathrm{~B}, 2 \mathrm{~N}$, or $3 \mathrm{VWD}$, then they should be able to fulfill the criteria for inclusion in 2M VWD.

Although not a true form of VWD, as the defect lies in the platelet VWF receptor (GPIb), platelet type (PT-) VWD (sometimes called "pseudo-VWD") also deserves to be mentioned. Some consider PT-VWD to be a kind of "cousin" to $2 \mathrm{~B}$ VWD, in which the patient's GPIb shows enhanced binding for plasma VWF (whereas in 2B VWD, the patient's plasma VWF shows enhanced binding for platelet GPIb). ${ }^{10}$ PT-VWD and 2B VWD show similar phenotypic features-loss of (HMW) VWF and (typically mild) thrombocytopenia. In both cases, "spontaneous" binding of VWF to platelet GPIb occurs and these platelets are cleared from the circulation. In PT-VWD, GPIb is the driver, and in 2B VWD, plasma VWF is the driver. Irrespective, as treatment differs (platelets for PTVWD and VWF replacement for 2B VWD), their discrimination is important (discussed below).

\section{VWF Assays}

In summary, VWD arises from defects and/or deficiency of VWF, and laboratory testing therefore assists clinical exclusion or diagnosis of VWD. ${ }^{4-7}$ Contemporary laboratory assays comprise a myriad of assays that identify the quantity (level) of VWF, as well as the multitude of VWFactivities. The primary assay of VWF is measurement of its level, which is achieved by an assay we called VWF antigen (VWF:Ag). ${ }^{7,11}$ Nevertheless, this assay can be performed by a myriad of methods, including ELISA (enzyme linked immunosorbent assay), LIA (latex [agglutination] immunoassay), and chemiluminescence immunoassay (CLIA; - Table 1). Laboratory testing for FVIII, mostly of its "coagulant activity," by means of FVIII:C assays ${ }^{12}$ is also required in VWD testing, given the close connection with level and functionality of VWF and consequent level and functionality of FVIII. Thus, FVIII levels are low in most forms of VWD, and especially in types 3 and 2N VWD.

There is also a requirement in VWD testing to assess for the functionality of VWF, and this is achieved using VWF "activity" assays. ${ }^{7}$ Here, there is considerable confusion amongst both clinicians and laboratory workers, given the misunderstanding about their "equivalence" or otherwise. Most available activity assay "interrogate" the effectiveness of GPIb binding, as representing one major activity of $\mathrm{VWF}^{7,13}$ Such assays include the classical ristocetin cofactor (VWF:RCo) assays. ${ }^{14}$ Given the recent explosion of assays reflective of GPIb binding, however, the ISTH SSC on VWF/VWD is now recommending a revised 
Table 1 Recommended nomenclature for VWF test parameters

\begin{tabular}{|c|c|c|}
\hline $\begin{array}{l}\text { Abbreviation } \\
\text { for assay }\end{array}$ & Description of assay & Comments \\
\hline VWF:Ag & von Willebrand factor antigen & $\begin{array}{l}\text { All assays that provide a quantitative level of VWF } \\
\text { protein, be it by ELISA, LIA, CLIA, or other } \\
\text { methodology }\end{array}$ \\
\hline VWF:CB & von Willebrand factor collagen binding capacity & $\begin{array}{l}\text { All assays that provide a quantitative level of VWF- } \\
\text { collagen binding capacity, be it by ELISA, CLIA, or } \\
\text { other methodology }\end{array}$ \\
\hline VWF:RCo & $\begin{array}{l}\text { von Willebrand factor ristocetin cofactor activity: } \\
\text { all assays that use platelets and ristocetin }\end{array}$ & $\begin{array}{l}\text { Historically, the only such assay type available was } \\
\text { that based on platelet agglutination. This has } \\
\text { changed with the advent of nonplatelet-based } \\
\text { methods. }\end{array}$ \\
\hline VWF:GPIbR & $\begin{array}{l}\text { All assays that are based on the ristocetin-induced } \\
\text { binding of von Willebrand factor to a recombinant } \\
\text { wild type GPIb fragment }\end{array}$ & $\begin{array}{l}\text { Essentially a VWF:RCo assay that does not use } \\
\text { platelets, and which currently comprises the } \\
\text { IL Werfen VWF:RCo assays, as performed by either } \\
\text { CLIA or LIA technology. These assays essentially } \\
\text { generate test results that are very similar to those } \\
\text { generated using other "standard" VWF: RCo assays } \\
\text { that utilize platelets. }\end{array}$ \\
\hline VWF:GPIbM & $\begin{array}{l}\text { All assays that are based on the spontaneous binding } \\
\text { of von Willebrand factor to a gain-of-function mutant } \\
\text { GPIb fragment }\end{array}$ & $\begin{array}{l}\text { Essentially a GPIb binding assay that does not use } \\
\text { platelets, and which currently comprises the Siemens } \\
\text { Innovance VWF Ac assay (by LIA), as well as non- } \\
\text { commercialized ELISA-based assays. These assays } \\
\text { essentially generate test results that are very similar } \\
\text { to those generated using VWF:RCo assays, but do not } \\
\text { use ristocetin in the assay. }\end{array}$ \\
\hline VWF:Ab & $\begin{array}{l}\text { All assays that are based on the binding of a mono- } \\
\text { clonal antibody (MAB) to a von Willebrand factor } A 1 \\
\text { domain epitope }\end{array}$ & $\begin{array}{l}\text { Essentially a VWF binding assay that utilizes a } \\
\text { monoclonal antibody; this currently comprises the IL } \\
\text { Werfen “VWF activity” assay (LIA), as well as ELISA- } \\
\text { based assays. These assays do not use ristocetin. }\end{array}$ \\
\hline VWF:FVIIIB & von Willebrand factor: factor VIII binding capacity & $\begin{array}{l}\text { All assays that provide a quantitative level of VWF- } \\
\text { factor VIII binding capacity, irrespective of specific } \\
\text { methodology. Generally performed by ELISA. }\end{array}$ \\
\hline VWF:pp & von Willebrand factor: propeptide & $\begin{array}{l}\text { Assays that provide a quantitative level of VWF } \\
\text { propeptide. Generally performed by ELISA. }\end{array}$ \\
\hline RIPA & $\begin{array}{l}\text { Ristocetin induced platelet aggregation } \\
\text { (agglutination) }\end{array}$ & $\begin{array}{l}\text { As assay performed as part of platelet function } \\
\text { testing, usually with a platelet aggregometer that } \\
\text { measures the sensitivity of plasma VWF to ristocetin } \\
\text { concentration. }\end{array}$ \\
\hline
\end{tabular}

Abbreviations: CLIA, chemiluminescence immunoassay; ELISA, enzyme linked immunosorbent assay; LIA, latex immunoassay; VWF, von Willebrand factor. Source: Adapted from Favaloro et $\mathrm{al}^{7}$ and Bodó et al. ${ }^{15}$

nomenclature. ${ }^{7,15}$ VWF:RCo assays using platelets, ristocetin and native GPIb remain "VWF:RCo," but those using other solid phase particles and recombinant GPIb are termed VWF: GPIbR. $^{7,15}$ Additional gain-of-function VWF assays using recombinant GPIb mutations reflecting VWF:GPIb binding assays similar to VWF:RCo and VWF:GPIbR but which do not employ ristocetin are termed VWF:GPIbM. ${ }^{7,15,16}$ Adding to the confusion, GPIb binding assays can be performed by a myriad of methods (-Table 1). Classical VWF:RCo is performed by platelet agglutination, but may be performed on a platelet aggregometer or on automated analyzers. For example, at least two manufacturers (Siemens and Stago) make assays that can be performed on their automated analyzers. VWF:GPIbR assays, reflecting a kind of modern VWF:RCo assay, are typically performed on automated analyzers and most often via LIA or CLIA procedures. VWF:GPIbM assays can be performed on automated analyzers via a LIA method, but can also be performed via ELISA. ${ }^{17}$ In general, all VWF:GPIb binding assays (i.e., VWF:RCo, VWF:GPIbR, VWF:GPIbM) are essentially "interchangeable" from a VWD-diagnostic viewpoint, in that they all measure some form of GPIb binding, although they will not always provide exactly identical test data on individual patients. Nevertheless, it is important to identify which assay is used in a laboratory in case unexpected findings are observed.

A separate category of distinct VWF activity assay is the collagen binding $(\mathrm{CB})$ assay $(\mathrm{VWF}: \mathrm{CB}){ }^{7,18} \mathrm{VWF}$ : $\mathrm{CB}$ testing is most usually achieved using either ELISA or CLIA based methodology. ${ }^{7,18,19}$ Like the GPIb binding test group, most VWF:CB assays are largely "interchangeable" from a VWDdiagnostic viewpoint, as they all measure a form of $C B$, although they will not always provide exactly identical test 
data on individual patients. Thus, it is again important to identify which assay is used in a laboratory in case unexpected findings are observed. In particular, different VWF:CB assays may have differential utility based on the type of collagen used, and also the effectiveness of the assay for differential sensitivity to HMW VWF and also to different VWF mutations. ${ }^{19,20}$ Also, VWF:CB by ELISA may provide different diagnostic outcomes to CLIA-based assays in some patient types, for example 2M VWD. ${ }^{19}$

Another test used by some laboratories is the VWF:Ab assay. Indeed, some laboratories use this test instead of a GPIb-binding assay for screening VWD. ${ }^{21}$ In reality, the VWF: $\mathrm{Ab}$ assay is not a VWF:GPIb binding assay, or indeed a VWF: $\mathrm{CB}$, but a "monoclonal antibody (MAB) binding assay," as expanded below.

The other main test used in VWD diagnostics is the assessment of VWF multimers on the basis of size (or MW) by gel electrophoresis. Here, classical methods are mostly based on in-house assays and are nonstandardized, complex, and time consuming. They are performed well in some specialized laboratories, but are subject to high error rates in general diagnostic practice. ${ }^{22,23}$ A commercial semiautomated method is now available which offers better standardization and faster turnaroundtime, but which may not be able to evaluate fine details around VWF multimer structures. $^{24,25}$

Finally, there are other assays used to further interrogate VWF function, for example (1) the VWF propeptide assay (VWF:pp), which mostly helps to identify VWD types sitting in type 1 with faster VWF clearance, ${ }^{26}$ and (2) the VWF-FVIII binding (VWF:FVIIIB). ${ }^{27}$ Neither of these assays is widely employed, and instead tends to be only offered by specialist laboratories. The VWF:FVIIIB is particularly pertinent to the accurate diagnosis of $2 \mathrm{~N}$ VWD, and its discrimination from hemophilia A.

\section{VWF:Ag}

As noted, this assay identifies the level of VWF protein in plasma. This assay identified protein can be functional (as in type 1 VWD) or functionally defective (as in type 2 VWD). The most common methodology utilized in 2020 is LIA, which is usually performed using automated analyzers. Most manufacturers of hemostasis analyzers and reagents offer their own commercial "solution" for VWF:Ag. ${ }^{28}$ An additional emerging method, by CLIA, is now available for use on the HemosIL AcuStar instrument. ${ }^{19}$ In theory, all VWF:Ag assays are "interchangeable" for the purpose of VWD diagnostics. However, external quality assessment (EQA) data show us that there are subtle differences between results of different VWF:Ag assays on a sample-by-sample test basis. In part, this variability reflects the use of different methods (different manufacturer kits, different instruments, different antibodies) and different assay calibrators. An example of EQA data reflective of such differences is shown in - Fig. 1.

This figure, for within-sample differences between test results between assays of a single "class" helps identify (1) the assay variation of any particular assay (spread of data values identified by yellow bars) and (2) for functional assays listed below, the relative sensitivity/insensitivity of a particular assay to loss of HMW VWF (the lower the values represented by the yellow bars, the more sensitive is that assay to loss of HMW VWF; conversely, the higher the values represented by the yellow bars, the less sensitive that assay is to loss of HMW VWF).

\section{VWF:RCo}

As noted, this assay identifies a "functional" activity of VWF binding to platelets via GPIb. This assay reflects the original VWF activity assay. ${ }^{13}$ Originally performed by a semiquantitative visual inspection method of platelet agglutination, the method was adapted for use on platelet aggregometers and later on automated analyzers. The assay suffers from several technical limitations, partially historical, including high assay variability and poor performance at low levels of VWF. 8,29 Another recognized limitation is the use of ristocetin, which binds to VWF and acts to unfold VWF to expose the GPIb binding site on VWF, but which may lead to false low values of VWF:RCo in patients with genetic variants affecting ristocetin-VWF binding, but not actually reflective of VWD. ${ }^{30}$ These shortcomings have inspired the development of modern replacements for VWF:RCo by VWF:GPIbR assays, as well as by VWF:GPIbM.

\section{VWF:GPIbR}

Assays under this category still utilize ristocetin (like VWF: $\mathrm{RCo})$ to initiate a change in VWF conformation that then permits GPIb binding, but instead of platelets utilize another solid phase (latex for LIA; magnetic particles for CLIA) as well as recombinant (not native) GPIb for VWF binding. ${ }^{7,15}$ The most common methodology is LIA, and most manufacturers of hemostasis instruments and reagents will have a commercial VWF:GPIbR "solution" for their customers. ${ }^{28}$ An additional emerging method, by CLIA, is now available for use on the HemosIL AcuStar instrument. ${ }^{19}$ In theory, all VWF:GPIbR assays are "interchangeable" for the purpose of VWD diagnostics, and also potentially interchangeable with VWF:RCo. However, EQA and other published data show us that there are subtle differences between results of different VWF:GPIbR assays on a sample-by-sample test basis. In part, this variability (similar to VWF:Ag) reflects use of different methods (different manufacturer kits, different instruments, different solid-phase particles) and different assay calibrators. An example of EQA data reflective of such differences is shown in -Fig. 1.

\section{VWF:GPIbM}

Assays under this category do not utilize ristocetin to initiate a change in VWF conformation that then permits GPIb binding, but instead use a mutated form(s) of platelet GPIb to which VWF will "spontaneously" bind. 7,15-17,30 This is "analogous" to adding platelets from a patient with PT-VWD to plasma, and assessing how well plasma VWF binds. There is only one commercial offering for this assay by LIA (Siemens Innovance VWF Ac assay) and this can be performed on Siemens analyzers, ${ }^{7,16,24,28}$ and in theory can also be adapted to nonSiemens analyzers. The other main assay type is ELISA, ${ }^{17,30}$ but this reflects different methodologies and reagents and is 
A

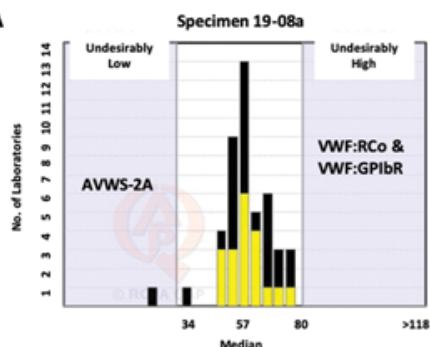

C

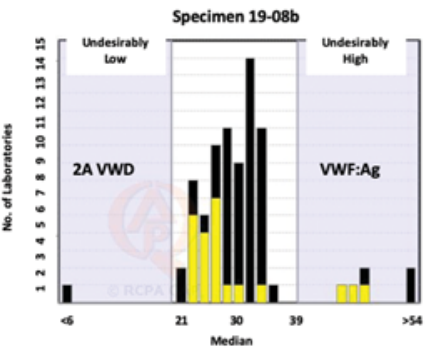

$\mathrm{E}$
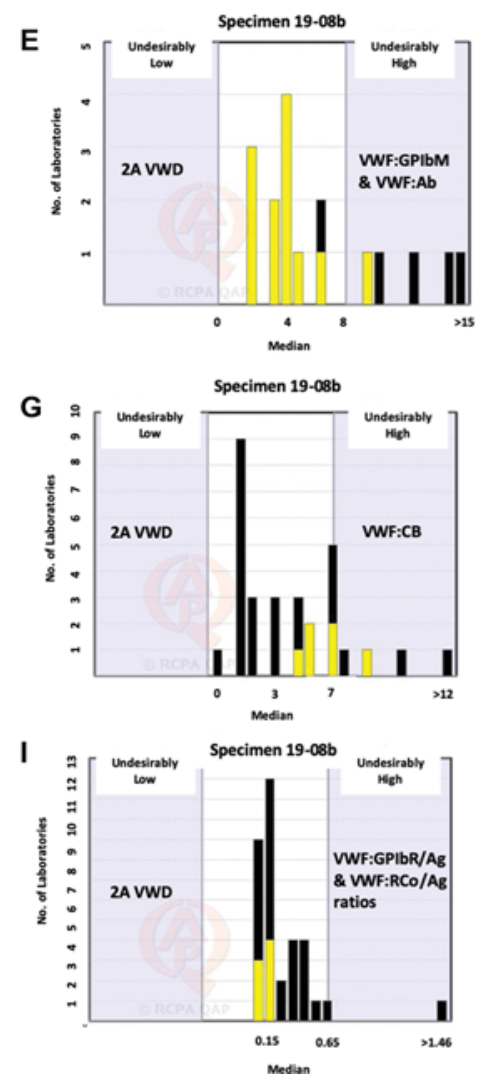

B
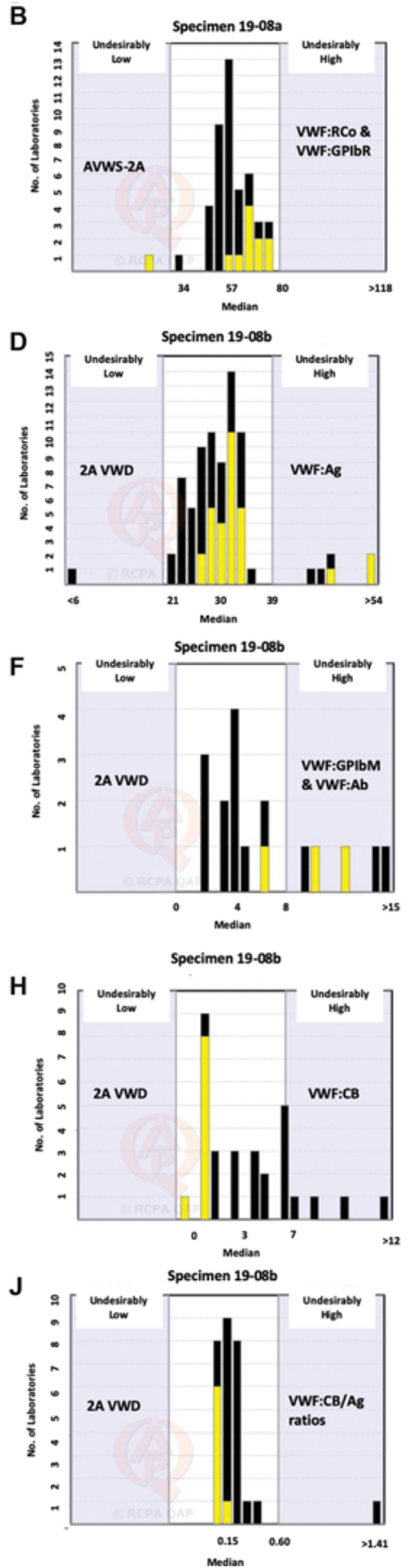

Fig. 1 Some examples from external quality assessment (EQA) that highlight some differences in test results even in the same "class" of VWF tests. Shown are some recent data (from 2019) from the RCPA QAP (Royal College of Pathologists Quality Assurance Program). Sample 19-08a (A, B) is meant to mimic an acquired von Willebrand syndrome with normal VWF:Ag but slight loss of HMW VWF ("AVWS-2A"). Sample 19-08b (C-J) is meant to mimic a 2A VWD-like sample ("2A VWD") with loss of HMW. In this EQA program, VWF:Ag assays comprise one test group and VWF:CB assays comprise another test group, but VWF:RCo and VWF:GPIbR are grouped together in a third group, and the residual VWF "activity assays" of VWF:GPIbM and VWF:Ab form a separate fourth group. Yellow bars identify results with a specific reagent as indicated below. Results with all other reagents of that assay class are shown as black bars. (A)VWF: RCo using Siemens reagent (yellow bars) showing wide spread of test results for this sample. (B)VWF:GPIbR using Instrumentation Laboratory assay on AcuStar instruments (yellow bars) showing generally higher test results compared with rest of class group for this sample. (C)VWF:Ag using Siemens reagent (yellow bars) showing generally low test results compared with rest of class group for this sample. (D)VWF:Ag using Diagnostica Stago reagent (yellow bars) showing generally higher test results compared with rest of class group for this sample. (E)VWF:GPIbM using Siemens reagent (Innovance VWF Ac; yellow bars) showing some spread of test results for this sample. (F)VWF:Ab using Instrumentation Laboratory assay (yellow bars) showing generally higher test results compared with rest of class group for this sample. (G)VWF:CB using Technoclone ELISA-based assay (yellow bars), showing generally higher test results compared with rest of class group for this sample. (H)VWF:CB using AcuStar CLIA-based assay (yellow bars), showing generally lower test results compared with rest of class group for this sample. (I)VWF:GPIbR/Ag ratio using Instrumentation Laboratory assays on AcuStar instruments (yellow bars) showing generally lower test results compared with rest of this class group for this sample. (J)VWF:CB/Ag ratio using Instrumentation Laboratory assays on AcuStar instruments (yellow bars) showing generally lower test results compared with rest of the $\mathrm{VWF}: \mathrm{CB} / \mathrm{Ag}$ group for this sample. 
not yet commercially available to this author's knowledge. Broadly speaking, VWF:GPIbM assays should provide similar diagnostic information as VWF:RCo and VWF:GPIR assays for the purpose of VWD diagnostics. However, EQA and other published data show us that there may be subtle differences between results of different VWF GPIb-binding assays on a sample-by-sample test basis, for similar reasons identified above for other assay types. An example of EQA data reflective of such differences is shown in - Fig. 1 .

\section{VWF:CB}

This class of assays identifies a separate activity of VWF, namely, binding to collagen. $7,18,20,31$ The main assay options are ELISA or more recently CLIA. The results of these assays are not interchangeable with those of GPIb-binding assays, and measure completely different functional aspects of VWF. Of course, in some patients with VWD (especially type 1), results will be similar to those of VWF:GPIb binding assays. However, results will be disparate in type 2 VWD, and indeed, the combined complementary results of VWF:CB and VWF:GPIb binding assays provide clues as to the likely defect in type 2 VWD. ${ }^{7}$ Broadly speaking, VWF:CB assays should provide similar diagnostic information to one another for the purpose of VWD diagnostics in most cases. However, EQA and other published data show us that there are substantive differences between results of different VWF: CB assays on a sample-by-sample test basis, for similar reasons identified above for other assay types, but also since some assays do not have good clinical utility. ${ }^{20}$ Moreover, the ELISA-based methods employ a wide variety of collagen types (primarily types I and III) in differing concentrations and mixtures, whereas the CLIA method uses a type III collagen peptide. How the collagen is applied to the ELISA plate, and other assay conditions, may also affect test results. $^{20,31}$ As noted, most commercial VWF:CB assays purport to using type I collagen or type III collagen or a mixture of types I and III collagen. ${ }^{20}$ In truth, this is difficult to confirm, since the main driver for VWF binding in VWF:CB seems to be type III collagen, and small "contaminating" quantities (even 1\%) of type III collagen may actually drive VWF:CB detection in a purported type I collagen assay. Other collagen types (IV and VI) have also been tried in VWD studies, ${ }^{32,33}$ but they have not in general generated commercial offerings, nor provided consistent findings in VWD patients. Some examples of EQA data reflective of differences between VWF:CB assays are shown in - Fig. 1.

\section{VWF:Ab}

This assay is marketed as an "activity" assay by commercial companies, and may be performed via either ELISA or LIA methods. ${ }^{21,34}$ The premise for this assay is binding of a MAB that recognizes a region of VWF that is involved in GPIb binding. Thus, VWF mutations that affect this epitope on VWF will not be detected by this MAB, and thus yield lower VWF test results. Thus, VWF:Ab assays have some sensitivity to type $2 \mathrm{~A}, 2 \mathrm{~B}$, and $2 \mathrm{M}$ VWD cases that may have altered structure of VWF. In addition, VWF:Ab assays can also be designed to have some sensitivity to loss of HMW VWF. ${ }^{34}$
Although some workers find the assay useful for VWD screening, in our experience, VWF GPIb-binding assays (VWF:RCo, VWF:GPIbR, VWF:GPIbM) and VWF:CB have overall greater utility and greater sensitivity to loss of HMW VWF, and would be preferentially recommended. ${ }^{34-36}$

\section{Use of Assay Panels and Assay Ratios}

Each test result on its own provides some information about the likelihood or not of VWD, as well as potential type of VWD if VWD is suggested, and also the potential severity of the disease. However, greatest utility in VWD diagnostics is achieved by the use of assay panels. Our laboratory continues to promote a minimal four-test panel comprising (1) VWF: $\mathrm{Ag}$, (2) VWF:CB, (3) FVIII:C, and (4) one or more VWF:GPIb binding assays (i.e., VWF:RCo, VWF:GPIbR, VWF:GPIbM). This recommendation mirrors that of the United KingdomHaemophilia Centre Doctors' Organization. ${ }^{5}$ Additional tests, including VWF multimers, and VWF:FVIIIB (and VWF:pp, etc.) may then be included based on results of the initial testing. This can be facilitated by means of an algorithmic approach to diagnosis, as shown simply in - Fig. 2, and more extensively in -Supplementary Fig. 1. Additional details around the utility of test panels and assay ratios are shown in - Table 2 and below.

In normal (non-VWD) individuals, the levels of all VWF assays should fall within the respective assay normal reference ranges (NRRs), or perhaps above those ranges. Importantly, similar values should be obtained with each VWF assay, so that all arising assay ratios should be close to unity. In practice, assay ratios above 0.7 are considered normal for most test combinations. In patients with type 1 VWD test patterns (i.e., VWF levels below their respective NRRs but similar values for each VWF assay), all assay ratios will again approximate unity, or as reflected by assay ratios above 0.7 for most test combinations. In both normal (non-VWD) and type 1 VWD individuals, this is called VWF assay "concordance." In patients with type 1 VWD test patterns, the level of VWF:Ag may help further stratify bleeding risk. For example, those with VWF:Ag below 10U/dL may be considered as suffering from "severe" type $1 \mathrm{VWD}$, whereas those with VWF:Ag between 10 and $30 \mathrm{U} / \mathrm{dL}$ may be considered as suffering from a moderate or mild form of type 1 VWD. Those with VWF:Ag between 30 and 50U/dL (or up to the lower cut-off value in the NRR for the assay) may instead be identified as having "low VWF" levels as a possible risk factor for bleeding, without actually being designated as having VWD. This is since the ability to establish a genetic cause for the VWF deficiency is higher the lower the level of VWF. Thus, a genetic mutation or variant will often be identified if VWF:Ag is $\leq 30 \mathrm{U} / \mathrm{dl}$, but not if $>30 \mathrm{U} / \mathrm{dL}^{6}$

In patients with type $2 \mathrm{VWD}$, there would be an expectation of a qualitative VWF defect, and thus test results with VWF activity assays may be much lower than that identified using VWF:Ag. In general, assay ratios $<0.5$ are consistent with representing assay "discordance" and reflective of a type 2 VWD test pattern. Assay ratios between 0.5 and 0.7 reflect a gray zone, which may or may not reflect assay discordance 


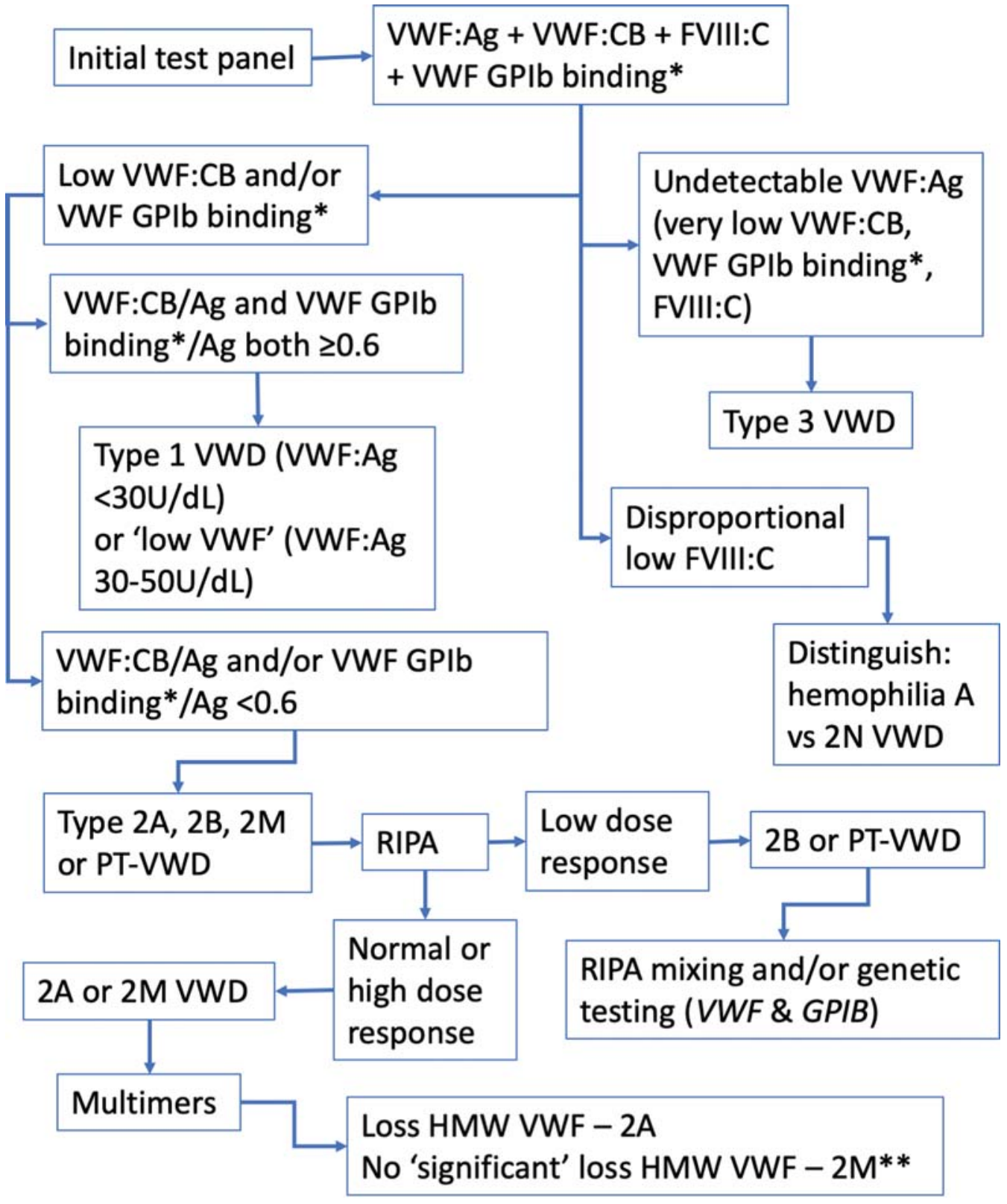

* VWF GPIb binding = VWF:RCo, VWF:GPIbR, VWF:GPIbM

\section{** usually VWF GPIb binding*/Ag $<0.6$ but VWF:CB/Ag $\geq 0.6$ Sometimes VWF:CB/Ag $<0.6$ and VWF GPIb binding*/Ag $\geq 0.6$ Sometimes VWF:CB/Ag and VWF GPIb binding*/Ag both $<0.6$}

Fig. 2 A simplified algorithm that describes a diagnostic process for VWD that considers the differential utility of different VWF methods, as well as VWF multimers, as modeled on the United Kingdom Haemophilia Centre Doctors' Organization guidance model. ${ }^{5}$ Ag, antigen; CB, collagen binding; FVIII, factor VIIII; GPIb, glycoprotein Ib (the platelet VWF receptor); GPIbM, GPIb mutation-based assay; GPIbR, recombinant GPIb-based assay; HMW, high molecular weight (VWF); RCo, ristocetin cofactor; RIPA, ristocetin-induced platelet aggregation; VWF, von Willebrand factor; VWD, von Willebrand disease.

based on the assays used. The United KingdomHaemophilia Centre Doctors' Organization guidance recommends a single cut-off of 0.6 for most assay ratios. ${ }^{5}$ This is also now employed in our laboratory, and reflects a reasonable "global" compromise approach. Nevertheless, there is some potential for some misclassifications, and test results usually need repeating for confirmation. This is because sample issues (preanalytical variables), assay limitations (including limits to assay precision for some assays), and intrapatient variability prevent definitive diagnosis based on a single round of testing. Some 


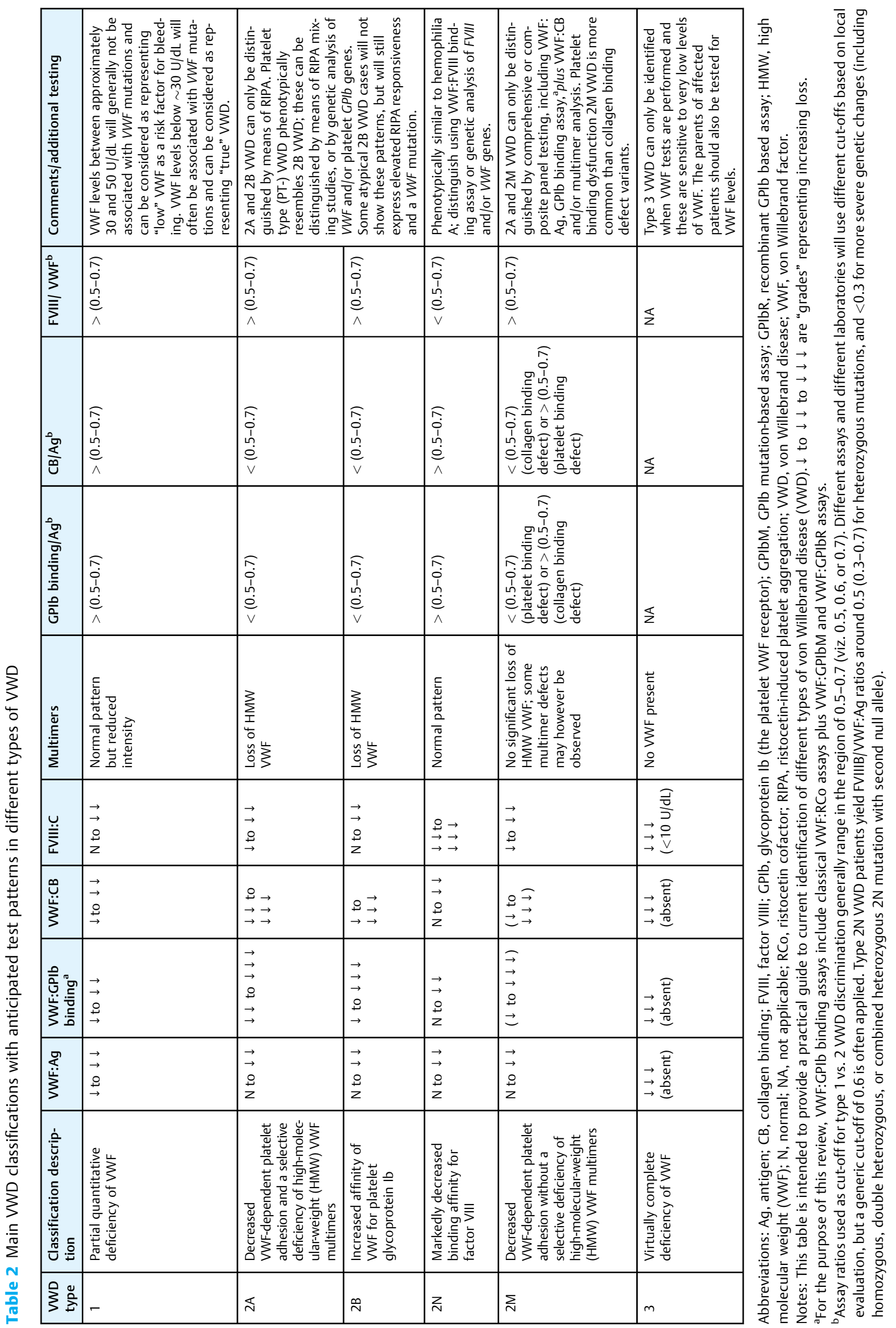


examples from EQA testing, and highlighting different test results on the same samples, are shown in - Fig. 3. In general, however, the lower the VWF activity/Ag assay ratios, the more likely a type 2 VWD diagnosis (baring preanalytical events), and the more normal the assay ratios, the more likely a type 1 or non-VWD diagnosis. However, in some patients with type 2 VWD, some assay ratios will actually be normal (concordant) while others are discordant-this is to be expected and provides clues to the actual VWD type (see below). Again, refer to -Fig. 3 for some examples.

Thus, in type 2A VWD, reflecting a loss of HMW VWF, one would expect to see universally reduced ratios of VWF "activity"/Ag (i.e., low VWF:CB/Ag, low VWF:RCo/Ag, low VWF:GPIbR/Ag, and low VWF:GPIbM/Ag). This is because all these activity assays are "similarly" sensitive to loss of HMW VWF, with this form of VWF normally representing the highest relative VWF "activity." In addition, however, the above-noted VWF activity assays are also all sensitive (but to potentially varying degrees) to the qualitative defect reflected by the presenting $V W F$ mutation.

In type 2B VWD, test findings with VWF assays will be similar to that of 2AVWD, with evident loss of HMW VWF and also sensitivity to the qualitative defect reflected by the presenting VWF mutation. Again, some differences between assays may be seen based on the extent of such sensitivity (i.e., reflecting a balance between the loss of HMW VWF and the respective VWF assay sensitivity to the hyper-adhesive VWF present in 2B VWD). In theory, since the level of HMW VWF loss is usually less than that observed in $2 \mathrm{~A} \mathrm{VWD}$, the assay ratios may not be as low as those observed in 2AVWD. On the other hand, differing assay sensitivity for the 2A versus $2 \mathrm{~B} V W F$ mutation-driven VWF conformational changes, plus the hyper-adhesive nature of $2 \mathrm{~B} \mathrm{VWF}$, can complicate assay ratio derivations and thus clear-cut separation of VWF assay ratios between $2 \mathrm{~A}$ and $2 \mathrm{~B}$ VWD is never achieved.

In $2 \mathrm{~N} \mathrm{VWD}$, the diagnostic clues are in the relative ratios of VWF and FVIII, as is also the case for hemophilia A. The VWF: FVIIIB assay can be used to differentiate $2 \mathrm{~N}$ VWD from hemophilia A. ${ }^{27}$ Otherwise, these disorders can only be differentially diagnosed by molecular investigation of $V W F$ and $F 8$ genes.

2M VWD provides a more complex pattern of assay ratios. In general, patients can be separated into three 2M VWD groups. The main group reflects patients with VWF mutations primarily affecting GPIb binding, and not affecting (or only weakly affecting) $\mathrm{CB}$. Some workers, including us, would assign these to a $2 \mathrm{M}_{\mathrm{GPIb}}$ subgroup of $2 \mathrm{M}$ VWD. In these patients, VWF: $\mathrm{CB} / \mathrm{Ag}$ ratios will generally be normal but VWF GPIb-binding assay/Ag ratios (i.e., VWF:RCo/Ag, VWF:GPIbR/ $\mathrm{Ag}$, and VWF:GPIbM/Ag) will be low ( - Fig. 3 shows some examples). The fact that VWF:CB/Ag ratios are normal in such patients will exclude a HMW VWF deficiency (and thus $2 \mathrm{~A}$ or $2 \mathrm{~B} V W D$ )-providing the VWF:CB assay in place is sensitive to such HMW VWF loss. A second rarer group of $2 \mathrm{M}$ reflects patients with $V W F$ mutations primarily affecting $C B$, and not affecting (or only weakly affecting) GPIb binding. Some workers, including us, would assign these to a $2 \mathrm{M}_{\mathrm{CB}}$ subgroup of 2M VWD. In these patients, VWF GPIb-binding
assay/Ag ratios (i.e., VWF:RCo/Ag, VWF:GPIbR/Ag, and VWF: GPIbM/Ag) will generally be normal but VWF:CB/Ag ratios will be low. ${ }^{37,38}$ The fact that VWF GPIb-binding assay/Ag ratios are normal will again exclude a HMW VWF deficiency (and thus $2 \mathrm{~A}$ or $2 \mathrm{~B} \mathrm{VWD}$ )-providing the VWF GPIb-binding assay(s) in place is sensitive to such HMW VWF loss. A third group of 2M reflects patients with VWF mutations affecting both CB and GPIb binding. These can only be differentiated from 2A VWD by means of multimer analysis, or potentially by genetic analysis of VWF.

\section{VWF Multimers}

Gel electrophoresis of VWF can separate VWF on the basis of size (MW) as well as identify other VWF structural defects. These assays can be performed as in-house assays, although utility depends on who performs the assay. In general diagnostic practice, there is a high error rate associated to use of VWF multimers (20-50\%), ${ }^{22,23}$ compared with classical phenotypic assays (around $10 \%) .{ }^{29}$ Conversely, in expert hands, VWF multimers can add considerable value to identification of specific VWD types, in particular to distinguish types $2 \mathrm{~A}$ and $2 \mathrm{M}$ VWD. An alternative commercial method is now available that can also in general distinguish $2 \mathrm{~A}$ and $2 \mathrm{M}$ VWD. ${ }^{24,25}$ Recognize, however, that VWD represents a continuous variable, with hundreds of separate VWF mutations identified, ${ }^{39}$ and thus some patients will still remain in an equivocal zone with exhaustive testing, even including VWF multimers and genetic testing. Be also aware that the commercial VWF multimer method cannot distinguish multimer changes in a triplet structure, as sometimes used to identify rarer forms of type 2 VWD.

\section{Additional Strategies for Diagnosing VWD}

This review has mostly focused on the myriad of VWF assays in use in laboratories and to diagnose or exclude VWD, and to provide for a better understanding of their differential utility. It is recognized, however, that such testing only comprises one phase of the investigation. If all VWF tests and FVIII:C are normal, especially if confirmed on a repeat (new) sample, then VWD is effectively "excluded." Naturally, given the complexity of VWD, $100 \%$ exclusion is never guaranteed, and there are rare forms of VWD that will yield normal test results for standard tests. As an example, some rare forms of 2B VWD will yield normal VWF tests but still show up with specific testing by RIPA (ristocetin-induced platelet aggregation) analysis (i.e., response to low concentrations of ristocetin) and also by genetic testing. As another example, we recently reported on a rare 2M VWD with normal VWF test results by all VWF test classes (VWF:Ag, VWF:RCo, and VWF: CB by ELISA, VWF:GPIbR, and VWF:GPIbM) that was only identified because abnormally low VWF:CB/Ag ratios were identified using a new VWF:CB assay based on CLIA. ${ }^{38}$ Also relevant is that VWF and FVIII:C represent acute-phase proteins, and may be elevated in individuals due to concurrent illness, or stress. ${ }^{40}$ Thus, VWF and FVIII:C may return normal test results in a patient with mild type $1 \mathrm{VWD}$, and 

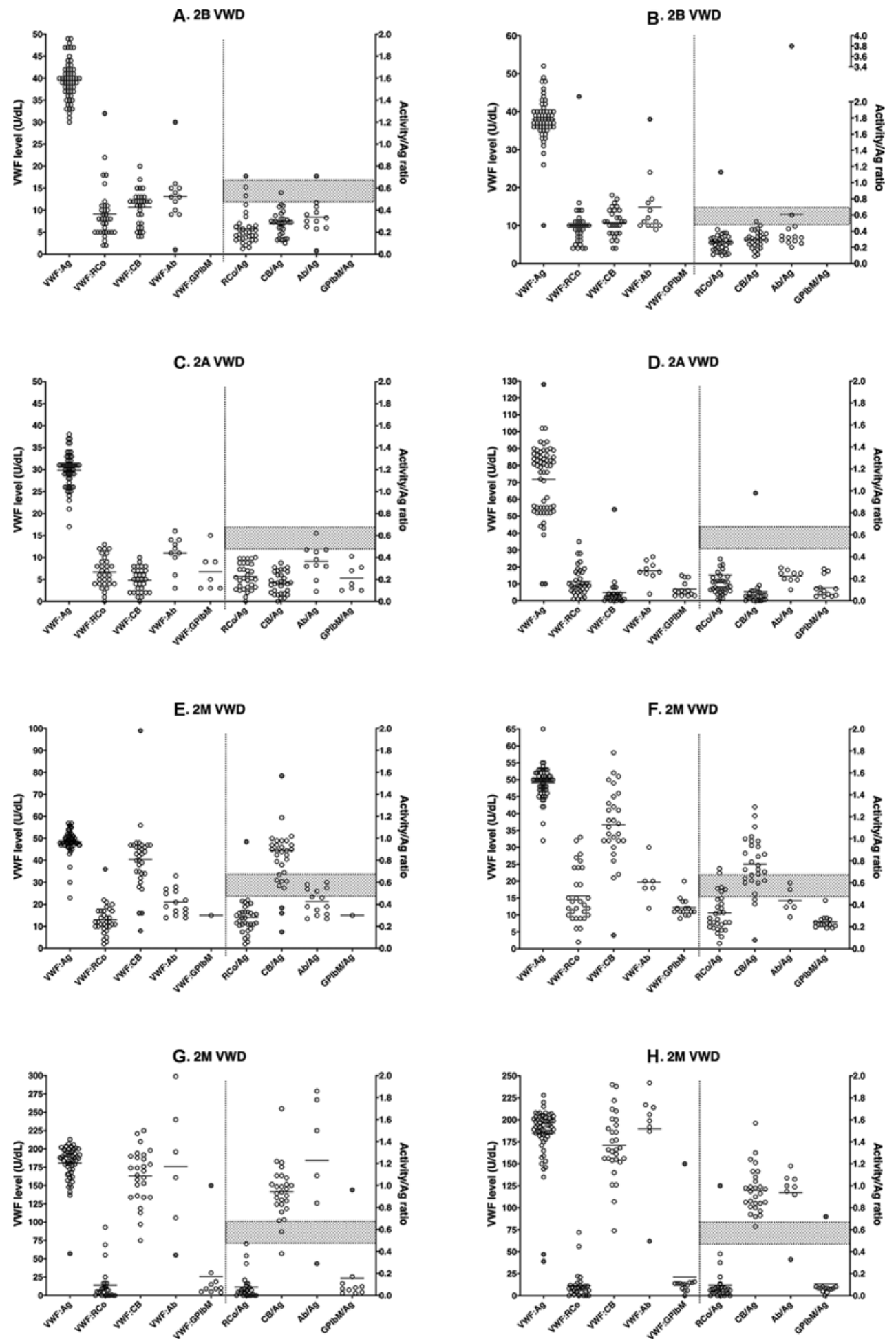

Fig. 3 Some examples from external quality assessment (EQA) that highlight some notable differences between different "classes" of VWF tests, as well as assay variability and occasional test errors (including some outliers identified in red filled symbols). Shown are some historical data from the RCPA QAP (Royal College of Pathologists Quality Assurance Program). Samples reflect different type 2 VWD samples (2B, 2A, 2M). The gray highlighted region on the right of each figure reflects an equivocal zone (between 0.5 and 0.7 ), whereas values $<0.5$ are reflective of a type 2 (VWF discordance) pattern, and values $>0.7$ are reflective of a type 1 (VWF concordance) pattern. (A) $2 B$ VWD sample. Several outliers noted. Note also the variability in assay data as well as assay ratio data. Some false VWF "concordance" events can be associated with a failure to identify type 2 VWD in this sample. (B) Another 2B VWD sample. (C) A type 2A VWDlike sample. (D) Another type 2A VWD-like sample. (E) A type 2M $\mathrm{M}_{\mathrm{GPIb}}$ sample. Some outliers noted, but most laboratories reported low VWF:RCo but normal VWF:CB/Ag ratios. For this sample, most laboratories using a VWF:Ab assay also reported generally lower VWF:Ab/Ag ratios. (F) The same type $2 \mathrm{M}_{\mathrm{GPIb}}$ sample as in (E), but tested on a separate occasion in a separate EQA exercise. (G) Another type $2 \mathrm{M}_{\mathrm{GPIb}}$ sample. Some outliers noted, but most laboratories again reported low VWF:RCo but normal VWF:CB/Ag ratios. For this sample, most laboratories using a VWF:Ab assay reported generally normal VWF:Ab/Ag ratios, but most laboratories using a VWF:GPIbM assay reported generally abnormal VWF:GPIbM/Ag ratios. (H) The same type $2 \mathrm{M}_{\mathrm{GPIb}}$ sample as in (G), but tested on a separate occasion in a separate EQA exercise. Ag, antigen; CB, collagen binding; GPIb, glycoprotein Ib (the platelet VWF receptor); GPIbM, GPIb mutation-based assay; RCo, ristocetin cofactor; VWF, von Willebrand factor; VWD, von Willebrand disease. 
thus mask their VWD. Usually, this may occur once, and not on repeat, or vice versa, but could occur on both initial and repeat tests. If there is a strong clinical suspicion of VWD, and test results return normal (especially if just above the NRR cut-off), then investigation of the acute phase may be helpful (e.g., testing of another acute phase protein at the same time as VWF testing). However, for the vast majority of patients, no additional testing by VWF assays is warranted in cases giving normal test results by the recommended four-test panel on two separate occasions, especially when results are very normal (e.g., >100U/dL).

For those patients showing low levels of VWF and showing VWF assay concordance (i.e., normal VWF activity/Ag ratios) on two separate test occasions, then a diagnosis of "low VWF" or type 1 VWD can be made based on the presenting level of VWF. In these patients, usually no other follow-up is required other than a DDAVP (1-desamino-8-d-arginine vasopressin; desmopressin) trial to evaluate responsiveness for potential therapeutic use. DDAVP promotes release of endogenously stored VWF and is effective for most clinical needs for most patients with type $1 \mathrm{VWD}$, and some patients with type 2 VWD. ${ }^{41,42}$ Some believe that DDAVP is contraindicated in type $2 \mathrm{~B} V W D$, due to a perceived worsening of thrombocytopenia. VWF replacement is otherwise the main alternate or supplementary treatment (most patients with type 2 VWD, all patients with type 3 VWD, and all patients with extended needs such as major surgery or protracted treatment).

Patients with low FVIII:C/VWF:Ag ratios should be evaluated for hemophilia A or 2N VWD. Most such patients, especially if male, will be with hemophilia A. If 2N VWD is considered possible, then testing by the VWF:FVIIIB assay and/or genetic testing of $V W F$ is advised; genetic testing of $F 8$ is suggested if confirmation of hemophilia A is alternatively required. There have also been a few isolated cases of combined defects identified, with mutations in both VWF and F8 identified in family members. Distinguishing 2N VWD and hemophilia $\mathrm{A}$ is important for therapy considerations, being VWF and FVIII replacement, respectively.

Patients with low ratios of VWF:CB/Ag and/or VWF GPIbbinding/Ag are subject to further evaluation. Certainly, repeat testing (on a fresh sample) for confirmation is needed. Then the follow-up depends on local feasibility. The first step in our laboratory is to perform RIPA analysis to identify/ distinguish $2 \mathrm{~B} / \mathrm{PT}-\mathrm{VWD}$ from $2 \mathrm{~A} / 2 \mathrm{M}$ VWD. ${ }^{43}$ If the patient responds to low-dose ristocetin, then $2 \mathrm{~B}$ VWD (or its rarer "cousin" of PT-VWD) ${ }^{10}$ is suggested. Then, repeat testing for confirmation (fresh sample) is again suggested. If confirmed, there is a requirement to distinguish 2B from PT-VWD, again based on differential therapy (VWF vs. platelet replacement, respectively). This can be achieved using RIPA-mixing studies $^{10,43}$ and confirmed by differential genetic testing of $V W F$ and GPIB genes. If RIPA testing excludes 2B (and PT-) VWD, then the cases should be differentially identified as either $2 \mathrm{~A}$ or $2 \mathrm{M}$. Here, the same therapy is typically assigned (VWF replacement); nevertheless, there may be differential bleeding risk (2M VWD cases may have reduced risk) and/or utility of DDAVP therapy. ${ }^{44}$ Our usual approach is to evaluate DDAVP responsiveness first, as this has both therapeutic implication and diagnostic utility-providing multiple time points at which to interrogate assay ratios. ${ }^{42} \mathrm{VWF}$ multimers can also help to distinguish 2A (loss of HMW) and 2M (no "significant" loss of HMW). Genetic testing is also progressed.

As noted before, such strategies are summarized in - Fig. 2 and extensively detailed in - Supplementary Fig. 1.

\section{Conclusion}

VWD is a common bleeding disorder and its diagnosis is facilitated by laboratory testing for VWF and FVIII:C. VWF tests take various forms, and are not identical. There are differences between the different classes of tests (-Fig. 3), as well as within the same test classes (-Fig. 1). This review has attempted to orientate the reader toward an understanding of these differences, and thus hopefully direct laboratories and clinicians to improved diagnosis and classification of VWD.

\section{Competing Interest}

The author has no competing interests.

\section{Acknowledgments}

The views expressed in this review are those of the author, and not necessarily those of NSW Health Pathology.

\section{References}

1 Yee A, Kretz CA. Von Willebrand factor: form for function. Semin Thromb Hemost 2014;40(01):17-27

2 Favaloro EJ. Diagnosis or exclusion of von Willebrand disease using laboratory testing. Methods Mol Biol 2017;1646:391-402

3 Bowman M, Hopman WM, Rapson D, Lillicrap D, James P. The prevalence of symptomatic von Willebrand disease in primary care practice. J Thromb Haemost 2010;8(01):213-216

4 Sadler JE, Budde U, Eikenboom JCJ, et al; Working Party on von Willebrand Disease Classification. Update on the pathophysiology and classification of von Willebrand disease: a report of the Subcommittee on von Willebrand Factor. J Thromb Haemost 2006;4(10):2103-2114

5 Laffan MA, Lester W, O'Donnell JS, et al. The diagnosis and management of von Willebrand disease: a United Kingdom Haemophilia Centre Doctors Organization guideline approved by the British Committee for Standards in Haematology. Br J Haematol 2014;167(04):453-465

6 Nichols WL, Hultin MB, James AH, et al. von Willebrand disease (VWD): evidence-based diagnosis and management guidelines, the National Heart, Lung, and Blood Institute (NHLBI) Expert Panel report (USA). Haemophilia 2008;14(02):171-232

7 Favaloro EJ, Pasalic L, Curnow J. Laboratory tests used to help diagnose von Willebrand disease: an update. Pathology 2016;48 (04):303-318

8 Favaloro EJ, Bonar R, Marsden K. Lower limit of assay sensitivity: an under-recognised and significant problem in von Willebrand disease identification and classification. Clin Lab Sci 2008;21(03): 178-183

9 Favaloro EJ, Bonar RA, Mohammed S, et al. Type 2M von Willebrand disease - more often misidentified than correctly identified. Haemophilia 2016;22(03):e145-e155

10 Favaloro EJ. Phenotypic identification of platelet-type von Willebrand disease and its discrimination from type $2 \mathrm{~B}$ von Willebrand disease: a question of $2 \mathrm{~B}$ or not $2 \mathrm{~B}$ ? A story of nonidentical twins? Or two sides of a multidenominational or multifaceted primaryhemostasis coin?. Semin Thromb Hemost 2008;34(01):113-127 
11 Favaloro EJ, Mohammed S, Patzke J. Laboratory testing for von Willebrand factor antigen (VWF:Ag). Methods Mol Biol 2017; 1646:403-416

12 Duncan E, Rodgers S. One-stage factor VIII assays. Methods Mol Biol 2017;1646:247-263

13 Just S. Laboratory testing for von Willebrand disease: the past, present, and future state of play for von Willebrand factor assays that measure platelet binding activity, with or without ristocetin. Semin Thromb Hemost 2017;43(01):75-91

14 Mohammed S, Favaloro EJ. Laboratory testing for von Willebrand factor ristocetin cofactor (VWF:RCo). Methods Mol Biol 2017; 1646:435-451

15 Bodó I, Eikenboom J, Montgomery R, Patzke J, Schneppenheim R, Di Paola J; von Willebrand factor Subcommittee of the Standardization and Scientific Committee of the International Society for Thrombosis and Haemostasis. Platelet-dependent von Willebrand factor activity. Nomenclature and methodology: communication from the SSC of the ISTH. J Thromb Haemost 2015;13(07): $1345-1350$

16 Patzke J, Favaloro EJ. Laboratory testing for von Willebrand factor activity by glycoproteinIbbinding assays (VWF:GPIb). Methods Mol Biol 2017;1646:453-460

17 Flood VH, Abshire TC, Christopherson PA, et al; Zimmerman Program Investigators. Von Willebrand disease in the United States: perspective from the Zimmerman program. Ann Blood 2018;3:7

18 Favaloro EJ, Mohammed S. Laboratory testing for von Willebrand factor collagen binding (VWF:CB). Methods Mol Biol 2017; 1646:417-433

19 Favaloro EJ, Mohammed S. Evaluation of a von Willebrand factor three test panel and chemiluminescent-based assay system for identification of, and therapy monitoring in, von Willebrand disease. Thromb Res 2016;141:202-211

20 Favaloro EJ. Evaluation of commercial von Willebrand factor collagen binding assays to assist the discrimination of types 1 and 2 von Willebrand disease. Thromb Haemost 2010;104(05): 1009-1021

21 Chen D, Tange JI, Meyers BJ, Pruthi RK, Nichols WL, Heit JA. Validation of an automated latex particle-enhanced immunoturbidimetric von Willebrand factor activity assay. J Thromb Haemost 2011;9(10):1993-2002

22 Chandler WL, Peerschke EI, Castellone DD, Meijer P; NASCOLA Proficiency Testing Committee. Von Willebrand factor assay proficiency testing. The North American Specialized Coagulation Laboratory Association experience. Am J Clin Pathol 2011;135 (06):862-869

23 Meijer P, Haverkate F. An external quality assessment program for von Willebrand factor laboratory analysis: an overview from the European concerted action on thrombosis and disabilities foundation. Semin Thromb Hemost 2006;32(05):485-491

24 Favaloro EJ, Oliver S, Mohammed S, Vong R. Comparative assessment of von Willebrand factor multimers vs activity for von Willebrand disease using modern contemporary methodologies. Haemophilia 2020;26(03):503-512

25 Oliver S, Vanniasinkam T, Mohammed S, Vong R, Favaloro EJ. Semi-automated von Willebrand factor multimer assay for von Willebrand disease: Further validation, benefits and limitations. Int J Lab Hematol 2019;41(06):762-771

26 Stufano F, Boscarino M, Bucciarelli P, et al. Evaluation of the utility of von Willebrand factor propeptide in the differential diagnosis of von Willebrand disease and acquired von Willebrand syndrome. Semin Thromb Hemost 2019;45(01):36-42
27 Mohammed S, Favaloro EJ. Laboratory testing for von Willebrand factor: factor VIII binding (for 2N VWD). Methods Mol Biol 2017; 1646:461-472

28 Favaloro EJ, Lippi G. Recent advances in mainstream hemostasis diagnostics and coagulation testing. Semin Thromb Hemost 2019; 45(03):228-246

29 Favaloro EJ, Bonar RA, Meiring M, et al. Evaluating errors in the laboratory identification of von Willebrand disease in the real world. Thromb Res 2014;134(02):393-403

30 Flood VH, Gill JC, Morateck PA, et al. Gain-of-function GPIb ELISA assay for VWF activity in the Zimmerman Program for the Molecular and Clinical Biology of VWD. Blood 2011;117(06): e67-e74

31 Favaloro EJ. An update on the von Willebrand factor collagen binding assay: 21 years of age and beyond adolescence but not yet a mature adult. Semin Thromb Hemost 2007;33(08):727744

32 Flood VH, Gill JC, Christopherson PA, et al. Comparison of type I, type III and type VI collagen binding assays in diagnosis of von Willebrand disease. J Thromb Haemost 2012;10(07):1425-1432

33 Larsen DM, Haberichter SL, Gill JC, Shapiro AD, Flood VH. Variability in platelet- and collagen-binding defects in type $2 \mathrm{M}$ von Willebrand disease. Haemophilia 2013;19(04):590-594

34 Favaloro EJ, Henniker A, Facey D, Hertzberg M. Discrimination of von Willebrands Disease (VWD) subtypes: direct comparison of von Willebrand factor:collagen binding assay (VWF:CBA) with monoclonal antibody (MAB) based VWF-capture systems. Thromb Haemost 2000;84:541-547

35 Favaloro EJ, Bonar R, Chapman K, Meiring M, Adcock DF. Differential sensitivity of von Willebrand factor (VWF) 'activity' assays to large and small VWF molecular weight forms: a crosslaboratory study comparing ristocetin cofactor, collagen-binding and mAb-based assays. J Thromb Haemost 2012;10(06):10431054

36 Favaloro EJ, Bonar R, Hollestelle MJ, et al. Differential sensitivity of von Willebrand factor activity assays to reduced VWF molecular weight forms: a large international cross-laboratory study. Thromb Res 2018;166:96-105

37 Favaloro EJ. Utility of the von Willebrand factor collagen binding assay in the diagnosis of von Willebrand disease. Am J Hematol 2017;92(01):114-118

38 Motum P, Just S, Zebeljan D, et al. A diagnosis of von Willebrand disease despite normal test results for factor VIII and von Willebrand factor antigen and activity. Am J Hematol 2019;94(12): 1425-1432

39 Zolkova J, Sokol J, Simurda T, et al. Genetic background of von Willebrand disease: history, current state, and future perspectives. Semin Thromb Hemost 2020;46:484-500

40 Cucuianu M, Pleşca L, Bodizs G, Colhon D, Brudaşcă I. Acute phase reaction and the hemostatic balance. Rom J Intern Med 1996;34 (1-2):13-18

41 Curnow J, Pasalic L, Favaloro EJ. Treatment of von Willebrand disease. Semin Thromb Hemost 2016;42(02):133-146

42 Favaloro EJ, Pasalic L, Curnow J. Monitoring therapy during treatment of von Willebrand disease. Semin Thromb Hemost 2017;43(03):338-354

43 Frontroth JP, Favaloro EJ. Ristocetin-induced platelet aggregation (RIPA) and RIPA mixing studies. Methods Mol Biol 2017; 1646:473-494

44 Favaloro EJ, Pasalic L, Curnow J. Type 2M and type 2A von Willebrand disease: similar but different. Semin Thromb Hemost 2016;42(05):483-497 